\title{
How to Solve the Problem of Poverty Alleviation by Education in Poor Areas
}

\author{
Xia Li \\ School of Tianjin University of Technology, Tianjin 300384, China \\ Email address:329575932@qq.com
}

Keywords: Poor areas; Education; Poverty alleviation

\begin{abstract}
Solving the ignorance and raising the intelligence is the first step to the poverty alleviation. The strategy of taking targeted measures for poverty in education is of great significance to the development of education in poor areas and the completing of a well-off society. Accurate poverty alleviation in education is an inevitable requirement for lasting poverty alleviation in poor areas. Based on a series of practical problems such as lagging economic, poor education conditions, weak teachers, and high school dropout rates in poor areas, the demand for accurate education for poverty alleviation has been continuously enhanced. By adjusting the economic structure, improving teaching facilities, improving the treatment of teachers, and developing vocational education in rural areas, the eradication of poverty in poor areas will be promoted. Building a well-off society, the rural areas, especially poor areas is the most arduous and heavy task. In poor areas, the way of general economic growth can not effectively boost local economic development and the measures of conventional poverty alleviation can not be effective in poor areas, thus the task of poverty alleviation is extremely difficult. Through accurate poverty alleviation in education, the poor areas fundamentally get rid of poverty and move towards a well-off society.
\end{abstract}

\section{The Need for Precision in Education Poverty Alleviation in Poor Areas}

Accurate poverty alleviation in education refers to using scientific and effective procedures to the poor figures and carry out accurately identify, accurately assist and accurately manage for different poor regions or different conditions of poor people. And by the accurate poverty alleviation in education, the poor people can obtain the skills and knowledge to fight poverty and ignorance, improve the scientific and cultural quality, promote all-round socio-economic and cultural progress and eventually move toward rich and prosperous. Accurate poverty alleviation in education can not only help wisdom, but help aspirations. It is objectively inevitable for poor areas to get rid of poverty.

\subsection{Accurate poverty alleviation in education is an inevitable requirement in poor areas}

Accurate poverty alleviation in education plays a fundamental and sustainable role in accurate poverty alleviation. And it is the need of China's poverty alleviation and development 
transformation. In order to completing of a well-off society, the state has continuously increased its support to poor areas. However, the efforts of the state in the contiguous special hardship areas have not received the expected results. Not only has the "blood transfusion" and "hematopoietic" projects yielded little results, but also the low income population has a high rate of return to poverty and the intergenerational transmission of poverty is obvious, which has seriously affected the progress of poverty eradication and enrichment in the concentrated contiguous special hardship areas.

We will carry out targeted measures for poverty alleviation in education, improving education development in contiguous poor areas, improving the knowledge level of the people in contiguous areas, and enhancing the ability to eradicate poverty and become rich. The UNESCO study found that the levels of productivity improvement of the educates at different levels, with undergraduate, junior 、 senior and elementary schools increasing productivity respectively by $300 \%, 108 \%$, and $43 \%$. The effectively combine "external impetus" with "endogenous impetus" can exert the key roles in accurate poverty alleviation in education. And the aim to improving the whole face for the concentrated contiguous special hardship areas and eventually achieving the efficacy of lasting poverty alleviation and enrichment.

\subsection{Accurate poverty alleviation in education is an inherent need for improving the ability of the population in poor areas}

Good education is an important way to change the fate of poor students and realize their life. Poor populations concentrated in contiguous poor areas suffer from low levels of education and lack of access to knowledge and skills, which limits individual development and causes them on the poor condition for a long time. Accurate poverty alleviation in education is to create an environment for poverty alleviation and support for wisdom, enhance the individual ability of the poor people in poor areas, letting the quality of the poor people get out of poverty, and then guide poor families to take the initiative to get rid of poverty and become rich. Improving the quality of poor people in all aspects and changing their ideas through accurate education and poverty alleviation; With this, their lives and production methods have also changed, so that the poor people have moved from passive receiving assistance to actively getting rid of poverty, actively seeking opportunities to get out of poverty, solving poverty problems, and completely eliminating poverty.

\subsection{Accurate poverty alleviation in education are effective ways to curb the intergenerational transmission of poverty in poor areas}

Looking at poverty in poor areas, it is an economic problem on the surface, but in essence, it is a cultural and conceptual problem. Once the culture falling behind, the economic development of this region has lost its internal impetus, leading to poverty, and developed into backward ideas. Children in poor families inherit the poverty and disadvantage of their parents, allowing them to repeat the situation of their parents in adulthood and pass poverty and disadvantage on to future generations. This is often referred to as the "intergenerational transmission of poverty." People's level of education is directly related to poverty. Education is the key to breaking the cycle of poverty in a vicious circle of low levels of education, where the quality of the labour quality is also lowly, affecting low economic incomes, leaving people living in poverty and, subsequently, affecting investment in education. We will train the poor population into a new generation of people who are ideological, brave, knowledgeable in science and technology, and well-managed through accurate poverty alleviation in education, so that the development of poor areas will produce endogenous impetus and hematopoietic functions. 


\section{The Dilemma of Education in Poor Areas}

With the improvement of the level of social and economic development, the level of teachers in the educational infrastructure of schools in poor areas of China has greatly developed and improved. But due to the lag in economic development in poor areas, the educational conditions have fallen behind and the teachers are weak. A series of practical reasons led to the increasing demand of local people for accurate education and poverty alleviation for the high dropout rate.

\subsection{Poor natural environment and economic lag have restricted the development of education in poor areas}

Natural geographical location is an important aspect that affects the economic development of a region. Areas rich in natural resources tend to have better prospects. Where the advantages of natural geographical location are not obvious, the economic development will have congenital defects. Owing to historical and natural reasons, it has caused widespread poverty, deep poverty, great difficulty in reducing poverty, and high cost of poverty eradication. The poor environment has restricted the development of the economy in concentrated contiguous special hardship areas. And the economic backwardness has seriously affected the development of education in these areas.

\subsection{Inadequate teaching facilities and backward educational conditions}

The teaching and education environment in poor areas is not optimistic, and the relative education lag has not been fundamentally changed. Since schools in poor areas are mostly located in remote and remote poor villages or on mountains, very inconvenient transportation leads to poor conditions in these areas. The school buildings are dilapidated, the classrooms are crowded, the supporting facilities are lacking, and there are no modern teaching tools such as computers and projections. Primary and secondary schools in more remote mountainous areas do not have modern teaching equipment, and teachers still use the most primitive method of teaching a chalk and a blackboard. Such backward teaching conditions and teaching links seriously affect the improvement of education and teaching, and it is difficult to rely on education to get the region out of poverty. If the school environment and infrastructure in poor areas are not effectively improved, then poverty eradication in these areas will become empty talk.

\subsection{Teachers ' mobility and weak teachers ' strength}

One of the key factors restricting the development of rural education in poor areas is the lack of a stable and high-quality teaching team. The aging of Teachers ' disposition, the low level of academic titles and the lack of teachers are serious problems. The main causes of these difficulties are: first, poor education environment, lacking of basic teaching tools and teaching facilities, restricting the ability of teachers to play and upgrade. Secondly, poor areas of teachers have many difficulties, such as living environment is relatively poor, traffic is difficulties, information is blocked. There do not have restaurants, bathhouse, vegetable market, etc. in some towns and villages. And this can not effectively meet the basic life needs of teachers. Thirdly, the low level of money in poor areas can not meet the needs of teachers to pay for marriage, children, housing, car and other consumer demand. Finally, teachers have not career prospects in poor areas, so that the teachers rooted in rural areas do not have hope. The professional development of teachers and the development of the next generation of children has a greater impact. This reasons cause many excellent teachers do not want to teach in poor area. The result is that rural introduce teachers is difficulties, and loss of teachers serious, and no teaching. 


\subsection{Poor students ' poor performance and high dropout rate}

Poor students ' poor performance and high dropout rate are the main obstacles to the development of education. In poor areas, there will be a phenomenon seriously restricts the cultivation of talent in the region that small rise in the beginning, rising high, high school up to a few stalls in descending, and the larger the gap between the grade. The reason is: firstly, low levels of economic development, lowly income, and the main expenses of the family in children's schooling costs, and in order to alleviate the burden of families, many school-age students drop out at home. Secondly, poor people's cultural quality is low, the education concept is backward, even think that college graduates are unemployed, rather than early earning a living. Thirdly, the rural migrant workers lead to the number of unhealthy body and mind left-behind children, who lack of parental and school education and care. This lead to a poor performance and high dropout rate.

\section{Solutions to education in poor areas}

Education is the basic project for the great rejuvenation of the Chinese. The prosperity of education is the prosperity of the country, and the strength of education is the strength of the country. In order to achieve accurate education and poverty alleviation in poor areas, it is necessary to accurately design education and poverty alleviation projects that meet the needs of poor people. The specific methods include:

\subsection{Adjusting economic development structure and consolidating the economic base of education development in poor areas}

The development of economy is the material foundation and the primary premise of realizing the development of education. However, for a long time, the limitations of various factors such as geographical environment and inconvenient transportation can not effectively support the development of education. Thus we must developed the local economy and education. Among them, the core is to speed up the adjustment of the industrial structure in the contiguous special hardship area and develop local characteristic industries. Based on the specific realities, the poor area can develop farming agriculture and forestry. In this way, it can not only play the local advantages to enhance the economic development stamina, but also highlight the local characteristics to maintain the ecological balance and enhance the ability of sustainable development. Only if we concentrate on the healthy and sustainable development of the economy in contiguous poor areas, can we provide more adequate resources and funds for the development of local rural education, so as to achieve accurate education and poverty alleviation and lasting poverty alleviation.

\subsection{Increase investment and improve educational and teaching facilities in poor areas}

To improve the quality of education and teaching in poor areas, it is necessary to strengthen the improvement of educational facilities and increase the efforts to alleviate poverty in education, including the policy and economic strength. The teaching environment in poor areas should start from the following aspects: Firstly, we must pay attention to the reconstruction or repair of school classrooms, dormitories, canteens, bathhouses and other infrastructure in the contiguous poor areas; The school is equipped with modern teaching tools, such as computers and projections to broaden the vision of rural students. Secondly, we need to speed up the development of information infrastructure in schools and improve the level of education informatization. We need to implement the "Internet $+"$ model in education poverty alleviation, and adopt online education methods such as MOOC and open classes. High-quality teaching resources were shared over the Internet to 
concentrated contiguous poor areas with low levels of education. Finally, we should pay attention to the psychological counseling of students in poor areas and cultivate students 'subjective initiative in learning. We can exchange students in different schools to improve and enhance learning methods and motivation. We will make great effort to improve rural education by transforming from hardware to software and from quantitative to qualitative, so as to reach a new level of precision poverty alleviation in rural areas.

\subsection{Improving the treatment of teachers and creating conditions for attracting and retaining talents in poor areas}

Teachers are the foundation of the development of education. And it is the key that improving the overall quality of teachers in impoverished areas to promote the sustainable development of education. The key factors behind education in poor areas are the difficulty of attracting and retaining excellent teachers, for which the following issues need to be addressed. Firstly, we will raise the living standards of teachers in rural areas, implement the living allowance policy for teachers in poor areas, gradually raise the standard of subsidies, and effectively improve working and living conditions. Secondly, we need to supplement the village teachers 'ranks through multiple channels. Excellent teachers can be transferred from urban schools, excellent students can be recruited from major universities, and senior teachers can be recruited from the society to supplement the village teacher team. Thirdly, university graduates are encouraged to carry out educational support activities in poor areas, that help rural children to receive more suitable education, and improve their comprehensive quality and ability by transporting young and high-quality teachers and practicing innovative educational methods. Finally, we should broaden the career development prospects of rural teachers, so that they can not see hope. In short, constantly attracting and stabilizing talents to participate in rural education in poor areas is a guarantee for improving the level and quality of rural education in poor areas, and an effective support for the development of outstanding talents in rural areas.

To sum up, it is a complex and arduous systematic project to help poor areas with accurate education, and this needs coordination and cooperation in all aspects. The poor natural conditions and weak economic base make the poverty alleviation is very difficult, however, we must face up to the difficulties, focusing our education on poverty alleviation, implement the main battlefield for poverty eradication in poor areas. And, under the strong leadership of the Party, we make effort to ensure that the peasants in the poverty-stricken areas receive real happiness and work with the whole country to move towards a well-off society.

\section{References}

[1] Jinping Xi. xijinping talks about governance[M]. Beijing: Foreign Languages Press, 2014,pp189.

[2] Xiang Zhang. Research on the mechanism of education precision poverty alleviation in contiguous poor areas[J]. Education Journal, 2016(6),pp23-26.

[3] Junhao Liu. Education Poverty Alleviation: From "Helping Education to Poverty" to "Relying on Education to Poverty Alleviation"[J].Renmin University of China Journal of Education, 2016(2),pp44-53.

[4] Jing Zhang. Study on poverty status and poverty alleviation strategies in the concentrated contiguous special hardship area in Luliang Mountain area[J]. Economic Research Reference, 2016(39),pp 23.

[5] Zhiwen Zhu.5 promotes education and poverty alleviation efforts to block the intergenerational transmission of poverty [ J] . Administrative reform, 2016(7),pp 4-10. 